\title{
A COMPARATIVE STUDY ON THE ACCURACY OF LIGHT EMITTING DIODE FLUORESCENT MICROSCOPY AND CONVENTIONAL SPUTUM SMEAR MICROSCOPY IN THE DIAGNOSIS OF PATIENTS WITH PULMONARY TUBERCULOSIS
}

\author{
K. Kishore Kumar ${ }^{1}$, K. Sai Samrat *2, S. Sony Reddy ${ }^{2}$. \\ ${ }^{1}$ Assistant Professor, Department of Pulmonary Medicine, Chalmeda Anand Rao Institute of Medical \\ Sciences,Bommakal, Karimnagar, Telangana, India. \\ *2 Junior Resident, Department of Pulmonary Medicine, Chalmeda Anand Rao Institute of Medical \\ Sciences,Bommakal, Karimnagar, Telangana, India.
}

\section{ABSTRACT}

\begin{abstract}
Aims/Objectives: To compare the efficacy of light emitting diode fluorescent microscopy (LED) over conventional sputum smear microscopy in diagnosing Mycobacterium Tuberculosis.

Materials and Methods: This comparative study was conducted in the department of Pulmonology In Chalmeda Anand Rao Institute Of Medical Sciences, Karimnagar from November-2015 to June- 2017. A total of 100 sputum samples were collected from patients suspected of pulmonary TB.

Results: Out of 100 cases which were included in the study, 17 cases showed sputum positivity on AO staining where as only 11 cases showed sputum positivity on ZN staining. Number of paucibacillary cases detected on AO staining were 7 , compared to only 2 on $Z N$ staining.

Conclusion: Hence our study concludes that AO staining with LED is more efficient over ZN stain in detecting Tuberculosis bacilli in sputum, especially the paucibacillary cases in the diagnosis TB.

KEY WORDS: Mycobacterium Tuberculosis, Sputum examination, Ziehl Neelsen Staining(ZN staining), AuramineO Staining (AO staining).
\end{abstract}

Address for correspondence: Dr. K. Sai Samrat, Junior Resident, Department Of Pulmonary Medicine, Chalmeda Anand Rao Institute Of Medical Sciences, Bommakal, Karimnagar, Telangana, India. E-Mail: saisamratk.78@gmail.com

\begin{tabular}{|l|l|}
\hline \multicolumn{3}{|c|}{ Online Access and Article Informtaion } \\
\hline Quick Response code & \multicolumn{1}{|c|}{ International Journal of Integrative Medical Sciences } \\
& \multicolumn{1}{|c|}{ ISSN (P): 2394 - 6318. ISSN (E): 2394 - 4137 } \\
www.imedsciences.com
\end{tabular}

\section{BACKGROUND}

Tuberculosis remains world's leading cause of death from a single infectious agent. Pulmonary tuberculosis is the most common presentation of tuberculosis (TB). For developing countries with a large number of cases and financial constraints, evaluation of rapid and inexpensive diagnostic methods has a great importance.

It continues to be the world's most important infectious cause of morbidity and mortality among adults. Nearly 9 million people develop TB disease each year, and estimated 1.6 million die from the disease [1].

Microscopy remains the most appropriate method till date, but it suffers from low sensitivity for paucibacillary samples, found more frequently among immune compromised patients co-infected with HIV [2]. This seriously 
jeopardizes the quality of Ziehl Neelsen (ZN) microscopy, further reducing its yield [3].

Direct microscopy for Acid Fast Bacilli (AFB) is a widely used method for the diagnosis and confirmation of pulmonary Tuberculosis. First of all, ZN stain has low sensitivity relative to fluorescent stain [4] and culture [5], secondly it takes more time to scan at least 300 field. Thirdly, it needs experienced microbiologists. Fourthly, it often misses the paucibacillary TB cases especially when the patient is co-infected with HIV. Technical error is also more common in cases of ZN staining [6].

The advantages of fluorescence staining procedure are that it is simpler and can be examined at a lower magnification than ZN (40x Vs 100x). It has been estimated that Fluorescent microscope (FM) may take up to $75 \%$ less time than ZN [4]. This advantage would be a tremendous benefit for overburdened laboratory system in many low resource settings. We, therefore, performed a study comparing the reliability of LED and ZN stained sputum smears in the diagnosis and sputum conversion of pulmonary tuberculosis.

\section{MATERIALS AND METHODS}

This comparative study was conducted in the department of PULMONOLOGY in CHALMEDA ANAND RAO INSTITUTE OF MEDICAL SCIENCES, KARIMNAGAR from November-2015 to June2017. A total of 100 sputum samples were collected from patients suspected of pulmonary TB. , according to the following inclusion and exclusion criteria. Detailed history of those patients was recorded. Thorough clinical examination was done.

During the study the spot and early morning sputum samples of patients those who come to the pulmonology department with the following complaints was collected:

a) Cough with sputum (more than 2wks)

b) Low grade Fever with evening rise

c) Associated with or without loss of weight

Two sputum samples were collected on two consecutive days from each patient (One spot and one early morning sample) in clean, sterile, heat proof, wide mouth containers. The processing of samples was carried out in a biosafety cabinet. Each sample was then subjected to ZN staining and Fluorescent Auramine - $O$ (AO) staining.

Permission to conduct the study was obtained from Institutional Ethics committee(IEC), CHALMEDA ANAND RAO INSTITUTE OF MEDICAL SCIENCES, KARIMNAGAR. Informed oral consent was obtained from all patients.

\section{INCLUSION CRITERIA}

- All patients with symptoms suggestive of pulmonary tuberculosis with or without past history of pulmonary tuberculosis

- Age group of $12 y$ rs to $80 y r s$

\section{EXCLUSION CRITERIA}

-Sputum mixed with blood

- Sputum mixed with food particles

Sputum which is more of saliva

\section{OBSERVATIONS AND RESULTS}

Out of 100 sputum samples collected, 11 and 17 sputum samples were found to be positive for AFB by $Z N$ and $A O$ staining respectively. The $Z N$ smear positivity rate and the $A O$ smear positivity rate in this study was $11 \%$ and $17 \%$ respectively.

Table 1: Showing number of positive cases and their grading by ZN staining.

\begin{tabular}{|c|c|}
\hline Grading & $\begin{array}{c}\text { Count of ZN } \\
\text { STAINING RESULTS }\end{array}$ \\
\hline $1+$ & 1 \\
\hline $2+$ & 4 \\
\hline $3+$ & 5 \\
\hline SCANTY & 1 \\
\hline NEG & 89 \\
\hline Grand Total & $\mathbf{1 0 0}$ \\
\hline
\end{tabular}

Out of 100 cases, ZN staining was negative in 89 cases and positive only in 11 cases.

Chart 1: Bar diagram showing number of positive cases and their grading by $\mathrm{ZN}$ staining.

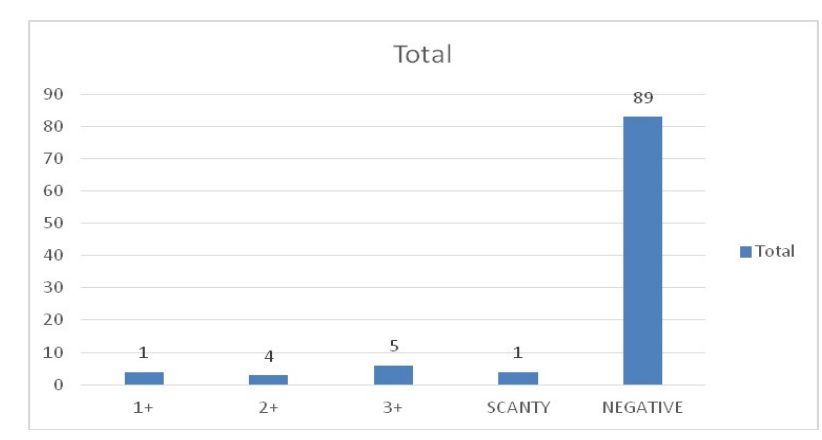


Table 2: Showing number of positive cases and their grading by $\mathrm{AO}$ staining.

\begin{tabular}{|c|c|}
\hline Grading & $\begin{array}{c}\text { Count of A-O } \\
\text { STAININGRESULTS }\end{array}$ \\
\hline $1+$ & 4 \\
\hline $2+$ & 3 \\
\hline $3+$ & 6 \\
\hline SCANTY & 4 \\
\hline NEGATIVE & 83 \\
\hline Grand Total & $\mathbf{1 0 0}$ \\
\hline
\end{tabular}

Out of 100 cases, AO staining was negative for 83 cases and positive for 17 cases.

Chart 2: Bar diagram showing number of positive cases and their grading by AO staining.

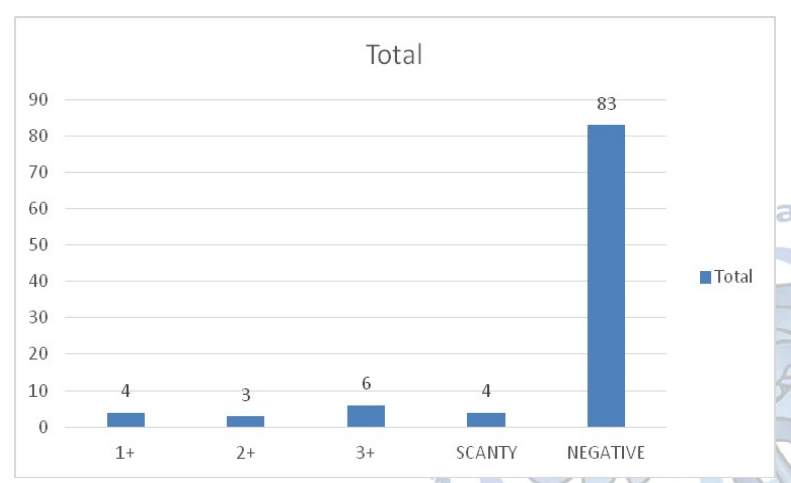

Table 3: Comparison of $\mathrm{ZN}$ and Auramine staining reports.

\begin{tabular}{|c|c|c|}
\hline & $\begin{array}{c}\text { No. of Positive } \\
\text { smears }\end{array}$ & $\begin{array}{c}\text { No. of Negative } \\
\text { smears }\end{array}$ \\
\hline ZN stain & $11(11 \%)$ & $89(89 \%)$ \\
\hline Auramine stain & $17(17 \%)$ & $83(83 \%)$ \\
\hline
\end{tabular}

Out of 100 cases, Auramine staining was negative for 83 cases as compared to 89 cases by ZN staining and positive for 17 cases as compared to 11 cases by ZN staining. . Similar results have also been reported by studies done by Suria Kumaret al, 2012 [7]. Whereas higher smear positivity rates were shown by K Prasanthi et al, $2005(50 \%$ by ZN, $69 \%$ by AO) [8] andUlukanligil et al ( $67.6 \%$ by $Z N, 85.2 \%$ by $A O)$ [9].

Chart 3: Bar diagram shows the positive smear results of $Z N$ staining and by Auramine $O$ staining by LED fluorescent microscopy.

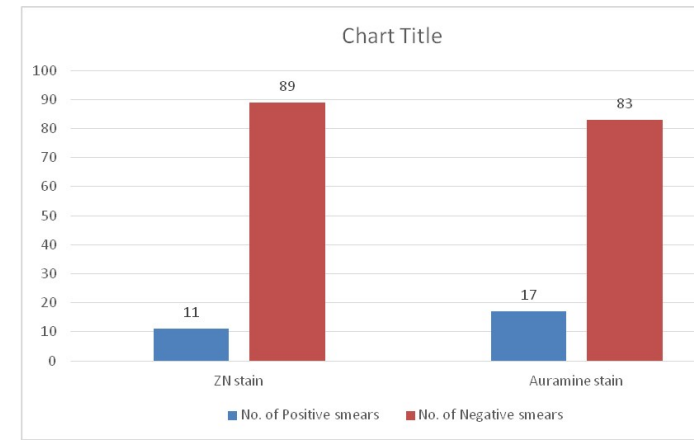

Int J Intg Med Sci 2018;5(9):736-40. ISSN 2394 - 4137
Table 4: Distribution of paucibacillary and multibacillary cases detected by ZN staining and LED fluorescent microscopy.

\begin{tabular}{|c|c|c|c|}
\hline Staining method & $\begin{array}{c}\text { No. of paucibacillary } \\
\text { cases }\end{array}$ & $\begin{array}{c}\text { No. of multibacillary } \\
\text { cases }\end{array}$ & $\begin{array}{c}\text { Total no. of positive } \\
\text { cases detected }\end{array}$ \\
\hline ZN staining & $2(18.1)$ & $9(81.9)$ & 11 \\
\hline Auramine staining & $7(41.1)$ & $10(58.9)$ & 17 \\
\hline
\end{tabular}

Number of Paucibacillary cases detected by Auramine staining are more in number compared to $\mathrm{ZN}$ staining.

In study conducted by Hooja S1, Pal N, Malhotra B, Goyal S, Kumar V, Vyas L. by title Comparison of Ziehl Neelsen \& Auramine $O$ staining methods on direct and concentrated smears in clinical specimens. The results are Using culture as the reference method, the sensitivity of direct staining was $55.55 \%$ for $Z N$ and $71.85 \%$ for AO. Direct fluorescent microscopy detected 9.29\% paucibacillary sputum samples that were missed on ZN staining. On concentration, the sensitivity increased by $6.67 \%$ for $Z N$ and $11.11 \%$ [10]. Whereas culture as a standard reference was not made in our study.

Chart 4: Distribution of paucibacillary and multibacillary cases detected by ZN staining and LED fluorescent microscopy.

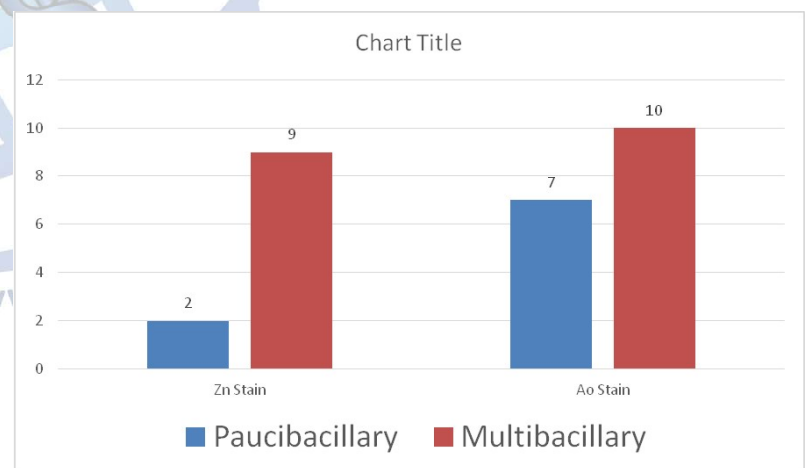

\section{DISCUSSION}

Current recommendations for the control of Tuberculosis emphasizeearly case detection so as to allow treatment of patients and there by limit the transmission of bacilli. ZN stain can detect bacilli when they are in the order of $10^{5}$ / $\mathrm{ml}$ of the sputum, where as a more sensitive AO stain can detect in the order of $10^{4} / \mathrm{ml}$ of sputum. In the present study out of the 100 samples examined, $11(11 \%)$ and $17(17 \%)$ TB cases were detected by $\mathrm{ZN}$ and $\mathrm{AO}$ staining methods respectively.

It was observed that a total no. of 6 sputum smears which were negative by ZN method were 
positive by $A O$ staining method and that $A O$ staining with LED Microscopy was more efficient over $\mathrm{ZN}$ stain in determining paucibacillary cases have also been proved in this study. AO staining could detect 7 paucibacillary cases, whereas ZNstaining detected only 2 of them. This was in concordance with studies done by Laifangbamal et al 2009 [11]. Failure to detect and hence to treat paucibacillary cases can be effectively prevented by the use of fluorescent LED microscopy. In the same Study conducted by Laifangbam S1, Singh HL, Singh NB, Devi KM, Singh NT ET al showed Out of 102 patients, $44.1 \%, 71.6 \%$ and $70 \%$ were found positive by $\mathrm{ZN}, \mathrm{AO}$ and culture respectively. AO was found to be superior to $Z N$ on several aspects. The difference in their case detection rates was statistically significant (chi $(2)=24.93$, $\mathrm{p}<0.001$ ). AO was also able to detect more Pauci-bacillary cases than ZN. There was more agreement between culture and fluorescence microscopy (95.1\%) than with ZN microscopy (69.6\%). The percentage of false negative by $\mathrm{AO}$ staining was only $2.78 \%$ which was in sharp contrast to that of ZN $(40.27 \%)$

In other study conducted by BaF, Rieder $\mathrm{HL}$ et al showed Concordance was $96.9 \%$ and $92.3 \%$ with $A O$ and $Z N$. The yield was similar with both techniques for specimens with at least 10 bacilli per 100 fields, but higher with fluorescence microscopy in those with fewer than 10 bacilli per 100 fields. The mean time required by fluorescence microscopy before declaring a slide as negative with the same magnification was 3 minutes 34 seconds, compared to 7 minutes 44 seconds with the Ziehl- Neelsen technique which was in similar fashion with our study [12].

In a study conducted by Dick van et al., 58 out Of the 221 sputum specimens evaluated, 36 (16.3\%) were positive for Mycobacterium tuberculosis by culture. Sensitivity and specificity documented for the different modalities were $84.7 \%$ and $98.9 \%$, respectively, for the LED assessment; $73.6 \%$ and $99.8 \%$, respectively, for the MVP assessment; and $61.1 \%$ and $98.9 \%$, respectively, for light microscopy. The mean time to read a negative smear was 1.4 min with fluorescence microscopy and $3.6 \mathrm{~min}$ with light microscopy, reflecting a time savings of $61 \%$ with fluorescence microscopy [13].

Table 5: Results of the study by Two Methods.

\begin{tabular}{|c|c|c|c|}
\hline Diagnostic modality & \multicolumn{2}{|c|}{$\begin{array}{c}\text { No. of sputum smear specimens } \\
\text { determined to be positive for } \\
\text { Mycobacterium tuberculosis } \\
\text { Microscopist 1 }\end{array}$} & $\begin{array}{c}\text { Microscopist 2 } \\
\text { discrepant } \\
\text { results }\end{array}$ \\
\hline Light microscopy & 23 & 25 & 10 \\
\hline $\begin{array}{c}\text { Fluoroscence microscopy } \\
\text { Mercury vapor lamp }\end{array}$ & 25 & 29 & 30 \\
\hline Light-emitting diode & 33 & 32 & 7 \\
\hline
\end{tabular}

As evident from the above table, the ability to detect mycobacterium tuberculosis is more on fluorescent microscope compared to light microscope. Among fluorescent microscope Light emitting diode is superior to Mercury Vapor Lamp.

In a study conducted by Jai Kishan Karahyla, staining and LED-FM both samples were positive in $98.48 \%$ cases and $96.24 \%$ cases respectively, however Sputum with Zn staining and LED-FM staining showed very narrow diference respectively [14].

In a comparative study on different staining methods for the detection of acid fast bacilli (Mycobacterium tuberculosis) in sputum samples conducted by Dr. Narayan Shrihari et al [15].The results obtained from ZN stained smears and fluorescent $(A O)$ stained smears were compared together, the result of our study revealed that $A O(11.43 \%)$ was nearly as sensitive as ZN (12.32\%)

In a study titled COMPARATIVE STUDY OF AURAMINE STAINING USING LED FLUORESCENT MICROSCOPY WITH ZIEHL-NEELSEN STAINING IN THE DIAGNOSIS OF PULMONARY TUBERCULOSIS done by Saroj Golia et al 634 sputum samples collected from suspected cases of pulmonary Tuberculosis were processed and subjected to $\mathrm{ZN}$ and Auramine-O (AO) staining for detection of TB. Positive smears were graded according to standard WHO criteria. Out of 634 sputum smears, $10.57 \%$ and $16.56 \%$ were positive by $Z N$ and $A O$ respectively. $A O$ was found to be superior to $Z N$ in detecting TB cases and also AO staining was able to detect more paucibacillary cases than ZN [16].

\section{CONCLUSION}

It can be concluded from our study that $A O$ staining with LED is more efficient over ZN stain 
K. Kishore Kumar, K. Sai Samrat, S. Sony Reddy. A COMPARATIVE STUDY ON THE ACCURACY OF LIGHT EMITTING DIODE FLUORESCENT MICROSCOPY AND CONVENTIONAL SPUTUM SMEAR MICROSCOPY IN THE DIAGNOSIS OF PATIENTS WITH PULMONARY TUBERCULOSIS.

in detecting Tuberculosis bacilli in sputum, especially the paucibacillary cases in the diagnosis TB.

\section{REFERENCES}

[1]. WHO, Global Tuberculosis Control Surveillance, Plan ning. WHO Report. WHO, Geneva, Switzerland, 2008;1-242.

[2]. Elliott A M, Namaambo K, Allen B W,et al. Negative sputum smear results in HIV positive patients with pulmonary tuberculosis in Lusaka, Zambia. Tubercle Lung Dis 1993;74:191-194.

[3]. Rieder H L, Van Deun A, Kam K M, Kim S J, Chonde T $M$, Trebucq A, Urbanczik R. Priorities for tuberculosis bacteriology services in low income countries. $2^{\text {nd }}$ ed. Paris, France: International Union against Tuberculosis and Lung Disease, 2007.

[4]. Steingert KR, Henry M, vi vienne. Fluorescence versus conventional sputum smear microscopy for tuberculosis, a systematic review. Lancet Infect Dis 2006;6:570-81.

[5]. Murry SJ, Barret A, Magee JG, Freeman R. Optimization of acid fast smears for the direct detection of mycobacteria in clinical samples. J Clin Pathology 2003;56:613-15.

[6]. Dinnes J, Deeks J, Kunst H, Gibson A, Gummins E, Waugh N, Drobniewski F, Lalvani A. A systematic review of rapid diagnostic tests for the detection of tuberculosis infection. Health Technology Assess 2007;11(3):1-196.

[7]. Dr. J. Suria Kumar. Dr. C. Chandrasekhar. Dr. S. Rajasekaran. Comparison of conventional and fluorescent staining methods in diagnosis of pulmonary tuberculosis among HIVseropositive individuals. Jr of evolution of med and dental sci.2012;1(4):463-466.

[8]. Prasanthi K, Kumari AR. Efficacy of fluorochrome stain in the diagnosis of pulmonary tuberculosis co-infected with HIV. 2005. Indian J Med Microbiol 2005;23:179-81.
[9]. Ulukanligil M, Aslan G, Tasci S. A comparative study on the different staining methods and number of specimens for the detection of acid-fast bacilli. Mem Inst Oswaldo Cruz. 2000;95:855-8.

[10]. By Hooja S, Pal N, Malhotra B, Goyal S, Kumar V, Vyas L. Comparison of Ziehl Neelsen \& Auramine $O$ staining methods on direct and concentrated smears in clinical specimens. Indian J Tuberc. 2011 Apr;58(2):72-6.

[11]. Laifangbam S, Singh HL, Singh NB, Devi KM, Singh NT. A comparative study of fluorescent microscopy with Ziehl-Neelsen staining and culture for the diagnosis of pulmonary tuberculosis. Kathmandu University Medical Journal 2009;7(3):226-230.

[12]. BaF, Rieder HL. A comparison of Fluorescence microscopy with the Ziehl-Neelsen technique in the examination of sputum for acid-fast bacilli. Int J Tuberc Lung Dis 1999;3:1101-05.

[13]. Dick van Soolingen, and Rob M. Warren Ben J. Marais, Wendy Brittle, Katrien Painczyk, Anneke C. Hesseling, Nulda Beyers, Elizabeth Wasserman. LED Fluorescence Microscopy to Detect AFB Lancet Infect Dis.2007;7(4):238-239.

[14].Jai Kishan Karahyla, Kamlesh Kumari, Pritpal KauAtwal. Staining. ERJ September 2013;42(1):P507

[15]. Shrihari N, Bact KS. A Comparison of three different staining methods for the detection of acid fast bacilli (Mycobacterium tuberculosis) in sputum samples. Journal of Pharmaceutical and Biomedical Sciences (JPBMS). 2012;14(14).

[16]. Golia S, Hittinahalli V, Nirmala AR, Sangeetha KT. Ziehl-Neelsen staining, Tuberculosis, Auramine-O, LED microscopy. A COMPARATIVE STUDY OF AURAMINE STAINING USING LED FLUORESCENT MICROSCOPY WITH ZIEHL-NEELSEN STAINING IN THE DIAGNOSIS OF PULMONARY TUBERCULOSIS. 2013 May; 16(1188).

How to cite this article: K. Kishore Kumar, K. Sai Samrat, S. Sony Reddy.
A COMPARATIVE STUDY ON THE ACCURACY OF LIGHT EMITTING
DIODE FLUORESCENT MICROSCOPY AND CONVENTIONAL SPUTUM
SMEAR MICROSCOPY IN THE DIAGNOSIS OF PATIENTS WITH
PULMONARY TUBERCULOSIS. Int J Intg Med SCi 2018;5(9):736-740.
DOI: $10.16965 /$ ijims.2018.131 